\title{
An updated view of kinetoplastid phylogeny using environmental sequences and a closer outgroup: proposal for a new classification of the class Kinetoplastea
}

\author{
Correspondence \\ David Moreira \\ david.moreira@ese.u-psud.fr
}

\author{
David Moreira, ${ }^{1}$ Purificación López-García ${ }^{1}$ and Keith Vickerman ${ }^{2}$ \\ 'UMR CNRS 8079, Ecologie, Systématique et Evolution, Université Paris-Sud, bâtiment 360, \\ 91405 Orsay Cedex, France \\ ${ }^{2}$ Division of Environmental \& Evolutionary Biology, University of Glasgow, Glasgow G12 800, UK
}

\begin{abstract}
Given their ecological and medical importance, the classification of the kinetoplastid protists (class Kinetoplastea) has attracted much scientific attention for a long time. Morphology-based taxonomic schemes distinguished two major kinetoplastid groups: the strictly parasitic, uniflagellate trypanosomatids and the biflagellate bodonids. Molecular phylogenetic analyses based on $18 \mathrm{~S}$ rRNA sequence comparison suggested that the trypanosomatids emerged from within the bodonids. However, these analyses revealed a huge evolutionary distance between the kinetoplastids and their closest relatives (euglenids and diplonemids) that makes very difficult the correct inference of the phylogenetic relationships between the different kinetoplastid groups. Using direct PCR amplification of $18 \mathrm{~S}$ rRNA genes from hydrothermal vent samples, several new kinetoplastid-like sequences have been reported recently. Three of them emerge robustly at the base of the kinetoplastids, breaking the long branch leading to the euglenids and diplonemids. One of these sequences belongs to a close relative of Ichthyobodo necator (a fish parasite) and of the 'Perkinsiella amoebae'-like endosymbiont of Neoparamoeba spp. amoebae. The authors have studied the reliability of their basal position and used all these slow-evolving basal-emerging sequences as a close outgroup to analyse the phylogeny of the apical kinetoplastids. They thus find a much more stable and resolved kinetoplastid phylogeny, which supports the monophyly of groups that very often emerged as polyphyletic in the trees rooted using the traditional, distant outgroup sequences. A new classification of the class Kinetoplastea is proposed based on the results of the phylogenetic analysis presented. This class is now subdivided into two new subclasses, Prokinetoplastina (accommodating the basal species I. necator and 'Perkinsiella amoebae') and Metakinetoplastina (containing the Trypanosomatida together with three additional new orders: Eubodonida, Parabodonida and Neobodonida). The classification of the species formerly included in the genus Bodo is also revised, with the amendment of this genus and the genus Parabodo and the creation of a new genus, Neobodo.
\end{abstract}

\section{INTRODUCTION}

Kinetoplastid protists belong, together with euglenids and diplonemids, to the phylum Euglenozoa (CavalierSmith, 1981). They are grouped in the class Kinetoplastea

Published online ahead of print on 12 March 2004 as DOI 10.1099/ ijs.0.63081-0.

Abbreviations: GTR, general time reversible; kDNA, kinetoplast DNA; LBA, long branch attraction; ML, maximum-likelihood; MP, maximumparsimony; $\mathrm{NJ}$, neighbour-joining; $\mathrm{PP}$, posterior probability.

The GenBank/EMBL/DDBJ accession numbers for the 18S rRNA gene sequences obtained from uncultured kinetoplastid-like species discussed in this study are AF530516 to AF530522.
(Cavalier-Smith, 1981), which is equivalent in composition to the order Kinetoplastida of previous classifications (Honigberg, 1963). The name of this group derives from the presence of a characteristic structure, the kinetoplast, which occurs as a mass of concentrated extranuclear DNA within the single mitochondrion (Vickerman, 1976). This kinetoplast DNA ( $\mathrm{kDNA}$ ) can display different distribution patterns, being massed close to the flagellar base (eukinetoplast) or scattered through the mitochondrion as several identical bodies (polykinetoplast) or unequally disseminated as diffuse masses (pankinetoplast). Not only is the peculiar arrangement of mitochondrial DNA unique among eukaryotes, but also some other features have attracted the attention of researchers upon this group for some time 
(Vickerman, 1990, 2000). For instance, significant diseasecausing parasites (such as Trypanosoma spp. and Leishmania spp.) belong to this class. On the other hand, free-living kinetoplastids are abundant and active microbial predators in terrestrial and aquatic ecosystems (Arndt et al., 2000; Foissner, 1991; Vickerman, 2000). A consequence of this interest has been a long quest towards the reconstruction of a robust phylogeny that provides a framework to study the origin and evolution of genetic, biochemical and structural traits in this group.

According to morphological criteria, kinetoplastids have been classified within two main suborders, the uniflagellate Trypanosomatina and the biflagellate Bodonina (Vickerman, 1976). Also on the grounds of morphology and ultrastructure, the suborder Bodonina has been subdivided in different families according to a number of concurrent classification schemes. Vickerman first proposed two families, Bodonidae and Cryptobiidae (Vickerman, 1976), although later on he re-unified all bodonids within a single family, Bodonidae (Vickerman, 1978, 1990, 2000). In contrast, the classification scheme proposed by Zhukov (1991) divides the Bodonina into two families: Bodonidae and Cephalothamniidae (Vickerman included Cephalothamnium in the Cryptobiidae). This confusing situation has not been clarified by the advent of molecular phylogenetic analyses of kinetoplastids one decade ago. The first molecular phylogenies, constructed using the 18S rRNA as marker, included a poor bodonid sampling (Landweber \& Gilbert, 1994; Maslov et al., 1994). More recent 18S rRNA phylogenies used a broader sampling but yielded contradictory results. For example, the common bodonid species Bodo saltans emerges (with a weak statistical support) as the closest relative to trypanosomatids in many rooted phylogenetic trees reconstructed using $18 \mathrm{~S}$ rRNA (Callahan et al., 2002; Lukeš et al., 2002; Simpson et al., 2000, 2002), CoxII (Blom et al., 1998) and Hsp90 (Simpson et al., 2002) sequences, but it is included within a large group of bodonids and cryptobiids in alternative 18S rRNA trees (Doležel et al., 2000). Moreover, the species emerging first in these rooted trees differ between the different analyses. A basal emergence in 18S rRNA trees has been thus suggested either for Cruzella marina and Bodo designis (Doležel et al., 2000), Cryptobia helicis and Bodo caudatus (Lukeš et al., 2002) or for Procryptobia sorokini (Callahan et al., 2002; Dyková et al., 2003). This uncertainty has precluded a reliable rooting of the kinetoplastid tree, making very difficult any inference about the evolutionary history of important traits in this group, such as the kDNA distribution or parasitism. Therefore, several authors have had recourse to unrooted trees for reconstructing more stable and better supported phylogenies to provide the framework required for the analysis of some of these characters (Doležel et al., 2000; Simpson et al., 2002). Using this strategy, the most comprehensive phylogenetic analysis of kinetoplastid $18 \mathrm{~S}$ rRNA sequences to date has recently lent support to the subdivision of bodonids within three strongly supported groups (Simpson et al., 2002). One of these groups, clade 3, containing the species B. saltans and 'Bodo cf. uncinatus', appears to be the closest relative to the trypanosomatids.

How do we explain these problems afflicting kinetoplastid phylogenies? Two concurrent factors are, at least partially, most likely responsible. The first is the use of very distant outgroup sequences to root the kinetoplastid tree. Most often, these are sequences from other euglenozoa (euglenids and/or diplonemids), although sequences from some slowevolving eukaryotic groups have also been used. All $18 \mathrm{~S}$ rRNA phylogenetic trees show a very long unbroken branch connecting the kinetoplastid sequences to the outgroup. It is usually the longest internal branch retrieved in these trees, with up to $\sim 20$ times the length of the longest internal branch within kinetoplastids (Simpson et al., 2002). This distant outgroup is an obvious source of phylogenetic instability, as demonstrated by the fact that removal of the outgroup helps to obtain more-robust trees (Doležel et al., 2000; Simpson et al., 2002). It has been consequently stated that 'it is clear that a resolution of this problem will require finding an outgroup more closely related to kinetoplastids or analysing another dataset' (Doležel et al., 2000). The second identified factor disrupting the kinetoplastid phylogeny is the massive accumulation of multiple overlapping mutations (mutational saturation) in the kinetoplastid sequences. The entire euglenozoan $18 \mathrm{~S}$ rRNA dataset exhibits a severe degree of mutational saturation, which has considerably hindered the reconstruction of the evolutionary relationships between euglenids, diplonemids and kinetoplastids (Moreira et al., 2001). As a result, removing the outgroup significantly increases the number of unambiguously aligned sites while simultaneously reducing the number of sites with multiple mutations (Doležel et al., 2000; Simpson et al., 2002). The confluence of a distant outgroup and mutational saturation can give rise to major phylogenetic reconstruction artefacts (Philippe \& Adoutte, 1998; Philippe \& Laurent, 1998). In fact, under these circumstances, the sequences tend to emerge according to their evolutionary rates rather than to their true phylogenetic affinities, i.e. the fastest evolving sequences are attracted towards the base of the tree by a long branch attraction (LBA) artefact (Philippe \& Adoutte, 1998; Philippe \& Germot, 2000; Philippe et al., 2000). In agreement with this, several rooted kinetoplastid trees show a most likely artefactual basal branching of the species Procryptobia sorokini, which corresponds to one of the longest branches in unrooted kinetoplastid trees (Callahan et al., 2002; Simpson et al., 2002).

Different, but not necessarily exclusive, hypotheses can be advanced to explain the unbroken long basal kinetoplastid branch. These include the extinction of intermediatebranching taxa, an abrupt acceleration of evolutionary rate at the origin of this group, or just an incomplete examination of the extant kinetoplastid diversity leading to an imbalanced taxonomic sampling in phylogenetic analyses. Under the first hypothesis, use of markers 
alternative to the rRNA will raise similar problems since for all of them the outgroup sequences will be very distantly related while, under the second hypothesis, it would be possible that alternative genes could have not suffered that hypothetical acceleration, so that they would provide closer and less-saturated outgroup sequences. A recent report seems to have discerned among these possibilities. The determination and phylogenetic analysis of the 18S rRNA sequence of the bodonid Ichthyobodo necator, formerly known as Costia necatrix, supported the view that this ectoparasite of fishes branches very deeply at the base of the kinetoplastid tree (Callahan et al., 2002). More recently, additional support has been published by Dyková et al. (2003), who found that 'Perkinsiella amoebae'-like organisms, found as endosymbionts of amoebae of the genus Neoparamoeba, are actually kinetoplastids related to $I$. necator, as revealed by the $18 \mathrm{~S}$ rRNA phylogenetic analysis. Therefore, intermediate kinetoplastid species breaking the long basal branch of the group appear to exist. We have recently confirmed this conclusion with the determination of three additional sequences branching at basal positions in the kinetoplastid tree. We retrieved these early-emerging sequences, together with those of several late-emerging bodonids, by PCR amplification and sequencing of $18 \mathrm{~S}$ rRNA genes directly from samples collected in the proximity of deep-sea hydrothermal vents in the Mid-Atlantic Ridge (López-García et al., 2003). In the present work, we have studied the impact of these environmental sequences on the kinetoplastid $18 \mathrm{~S}$ rRNA phylogeny. Their incorporation in the analyses, together with those from the genera Ichthyobodo and Perkinsiella, provides a closer outgroup that stabilizes the kinetoplastid tree. This allows retrieval of the monophyly of clades that otherwise emerge as paraphyletic or polyphyletic in most phylogenetic trees constructed using the traditional, distant outgroup sequences. Our speciesrich $18 \mathrm{~S}$ rRNA phylogenetic tree has provided us with the basis to propose a revised classification of the Kinetoplastea within two subclasses (Prokinetoplastina and Metakinetoplastina) and five orders (Prokinetoplastida, Eubodonida, Parabodonida, Neobodonida and Trypanosomatida), which accommodate virtually all described kinetoplastids.

\section{METHODS}

Seven 18S rRNA gene sequences from uncultured kinetoplastid-like species were obtained by PCR amplification using eukaryotic-specific primers and DNA extracted from several environmental samples collected in deep-sea hydrothermal areas of the Mid-Atlantic Ridge at depths between 1695 and $2264 \mathrm{~m}$ (for details, see López-García et al., 2003). These sequences were automatically incorporated and aligned within a large alignment containing 2481 18S rRNA gene sequences retrieved from GenBank (http://www.ncbi.nlm.nih.gov/). The multiple alignment was then manually edited using the program ED from the MUST package (Philippe, 1993). Gaps and ambiguously aligned positions were excluded from our analyses. A preliminary phylogenetic analysis of all these eukaryotic sequences was done by neighbour-joining (NJ) using the MUST package (Philippe, 1993). This analysis allows the unambiguous ascription of the new seven sequences to the Kinetoplastea (López-García et al., 2003).
From the large eukaryotic alignment, different kinetoplastid datasets (with or without sequences from other eukaryotic clades as outgroup) were constructed. For all these datasets, the corresponding maximumparsimony (MP) trees were used to estimate the parameter values for a general time reversible (GTR) model of nucleotide substitution, with an eighth-category discrete approximation of a $\Gamma$ distribution plus invariable sites (GTR $+\Gamma+I$ model), using the program PAUP ${ }^{*} 4 \mathrm{~b} 10$ (Swofford, 2000). In fact, in all cases the program MODELTEST (Posada \& Crandall, 1998) selected the GTR $+\Gamma+I$ model as the best of 56 testable substitution models. NJ and maximum-likelihood (ML) analyses using this model were carried out with PAUP* $4 \mathrm{~b} 10$ (Swofford, 2000). The ML trees were constructed using 100 random additions of species and the Tree Bisection-Reconnection (TBR) branch swapping option. Bootstrap replicates $(n=1000)$ were performed for all datasets. MP trees were constructed by 100 random taxon additions and TBR branch swapping, and Mulpars and steepest descent option activated. Bootstrap replicates $(n=1000)$ were performed for all datasets. Bayesian analyses (with a GTR $+\Gamma+I$ model) were carried out using the program MrBayes 3 (Huelsenbeck \& Ronquist, 2003). The Markov chain Monte Carlo search was run with four chains for 1000000 generations, with trees being sampled every 100 generations (the first 1500 trees were discarded as 'burnin'). Statistical comparisons of alternative tree topologies were done using the program CONSEL (Shimodaira \& Hasegawa, 2001). Mutational saturation diagrams were constructed using the program COMP_MAT from the MUST package (Philippe, 1993). Alignments are available upon request.

\section{RESULTS AND DISCUSSION}

\section{Identification of basal kinetoplastid-like sequences}

Callahan et al. (2002) recently reported the phylogenetic analysis of the 18S rRNA gene sequence of the bodonid I. necator, which is an important ectoparasite of fish. Using a ML phylogenetic analysis, they retrieved a strong bootstrap support $(100 \%)$ for the basal emergence of this species before the rest of kinetoplastid taxa. However, this basal position appeared to be unstable, since analyses using diplonemids as the only outgroup and analyses carried out with other tree reconstruction methods supported other branching locations for this bodonid (Callahan et al., 2002). Moreover, Simpson et al. (2002) noticed that the $18 \mathrm{~S}$ rRNA gene sequence from $I$. necator appears to be very divergent and that its phylogenetic position in unrooted analyses is unstable. As a consequence, its basal emergence in the rooted analyses could be due to an artefactual attraction to the outgroup sequences, i.e. an LBA artefact. One way to examine this possibility is by the incorporation of additional sequences related to $I$. necator, since it is well known that increasing the taxonomic sampling can help to alleviate LBA problems (Hendy \& Penny, 1989).

Therefore, in addition to the sequence of the 'Perkinsiella amoebae'-like endosymbiont (hereafter referred to as 'Perkinsiella cf. amoebae') determined by Dyková et al. (2003), we have incorporated into the phylogenetic analyses three additional basal-branching putative kinetoplastid sequences. These were recently retrieved from an $18 \mathrm{~S}$ rRNA-based survey of protist diversity from different substrates around deep-sea hydrothermal vents at the 

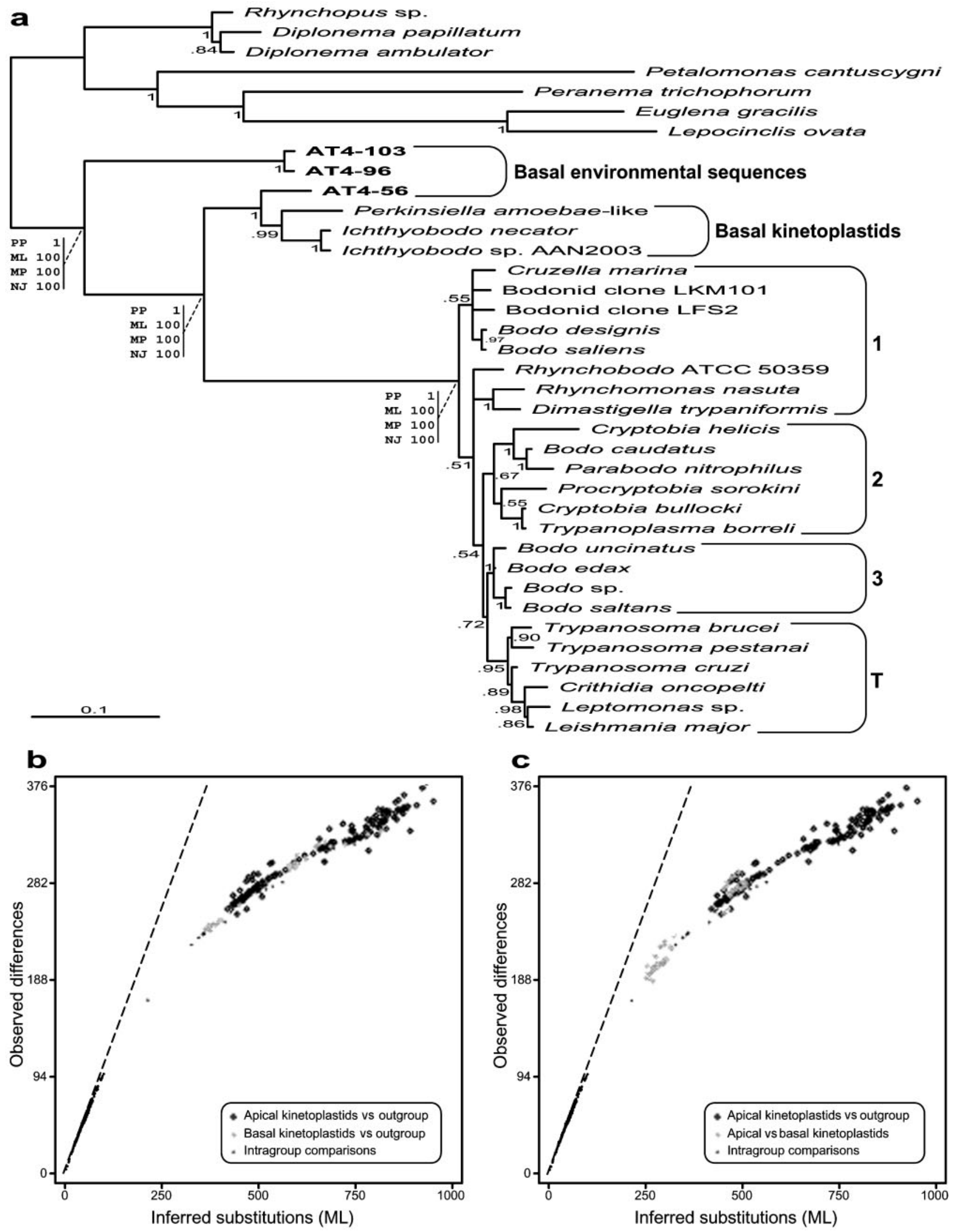
Mid-Atlantic Ridge (López-García et al., 2003). All our phylogenetic analyses, carried out using distance (NJ), MP, ML and Bayesian tree reconstruction methods, and a variety of sequence evolution models and of ingroup and outgroup sequences, recovered again the basal emergence of I. necator and 'Perkinsiella cf. amoebae' with a strong statistical support (see Fig. 1 for a Bayesian tree). In addition, our environmental sequence AT4-54 branches as a sister group of I. necator and 'Perkinsiella cf. amoebae', while the two other environmental sequences, AT4-96 and AT4103 , branch still deeper at the base of the kinetoplastid subtree. This result is in agreement with our previous analysis using a narrower euglenozoan sampling but a much wider representation of different eukaryotic lineages (López-García et al., 2003). The congruence between the different analyses with an increased taxonomic sampling suggests that the basal position of I. necator, 'Perkinsiella cf. amoebae' and the three environmental sequences is correct and not the result of an artefactual attraction towards the outgroup sequences.

Nevertheless, it is still possible that these congruent results arose by an LBA artefact, especially if the sequences emerging at the base are indeed very divergent, which can induce their branching at a midpoint position. We have addressed this question by studying the degree of mutational saturation for the complete set of euglenozoan sequences presented in Fig. 1. For each possible pair of sequences, we plotted the number of observed differences against the number of substitutions calculated upon an ML tree (Philippe et al., 1994). The diagram obtained shows that the number of substitutions calculated between the diplonemid + euglenid outgroup sequences and the five basal sequences is in general smaller than the number of substitutions between the outgroup sequences and the other (hereafter referred as to 'apical') kinetoplastid sequences (Fig. 1b). This would not be expected if the basal sequences were just very divergent ones. On the contrary, our results suggest that their basal position is correctly inferred. Additional support for this was obtained by comparing the preferred Bayesian tree topology (i.e. with I. necator, 'Perkinsiella cf. amoebae', AT4-54, AT4-96 and AT4-103 branching at the base of the kinetoplastid subtree) against different topologies where the basal sequences were constrained to branch at different positions within the apical kinetoplastid groups. The apical branching for these basal sequences was significantly rejected by the Shimodaira's approximately unbiased (Shimodaira, 2002) statistical test (data not shown).

A final source of evidence was lent by the close inspection of the sequence alignment. The $18 \mathrm{~S}$ rRNA gene sequence of $I$. necator, 'Perkinsiella cf. amoebae' and the three environmental sequences may appear to be very divergent when they are compared exclusively with the apical kinetoplastid sequences. However, many of the differences correspond to positions that are conserved in the outgroup sequences, including not only diplonemids and euglenids, but also other eukaryotes (Fig. 2). This suggests that these sequences are indeed less divergent than the apical kinetoplastid sequences, in agreement with their emergence at the base of the kinetoplastid tree.

We, therefore, have a set of five slow-evolving $18 \mathrm{~S}$ rRNA gene sequences that help to break the long basal branch leading to the apical kinetoplastid sequences. These sequences provide a closer outgroup to study the phylogenetic relationships among the apical kinetoplastids. They can also be used as slow-evolving representatives of the Kinetoplastea to study the position of this class within the Euglenozoa.

\section{5 rRNA phylogeny of the trypanosomatids and bodonids rooted on the basal kinetoplastid-like sequences}

As shown before, the basal sequences can provide an outgroup for the analysis of the apical kinetoplastid phylogeny that is closer than the sequences traditionally used to root the kinetoplastid tree (i.e. diplonemids and euglenids). A mutational saturation analysis for the dataset used to construct the tree in Fig. 1 shows that the pairwise sequence comparisons involving 'basal' versus 'apical' kinetoplastids are much less saturated by multiple substitutions than the sequence comparisons involving euglenids or diplonemids versus apical kinetoplastids (Fig. 1c). Therefore, the basal sequences, although still quite distant, constitute a much more appropriate outgroup to examine the phylogeny of the apical kinetoplastid groups.

Fig. 3 shows a Bayesian tree constructed using a GTR model with a $\Gamma$ law with eight discrete rate classes plus invariant sites $(\mathrm{GTR}+\Gamma+I)$ and rooted on the basal kinetoplastid

Fig. 1. (a) Bayesian phylogenetic tree of euglenozoan 18S rRNA sequences showing the position of several basal kinetoplastid species. Environmental sequences from deep-sea hydrothermal settings are in bold. Numbers at nodes are posterior probabilities except for the nodes concerning the basal kinetoplastids, for which the PP and ML, MP and distance(NJ) bootstrap proportions are shown. The apical bodonid clades 1, 2 and 3 are named according to Simpson et al. (2002), T coding for the Trypanosomatida. The tree was constructed using 1150 aligned sites. The scale bar represents the number of substitutions per position. (b) Mutational saturation analysis for the euglenozoan 18S rRNA sequences. The dashed line represents the ideal case where the number of inferred substitutions is equal to the number of observed differences between pairs of sequences. Small points correspond to intragroup comparisons, open circles to comparisons of apical kinetoplastid versus outgroup (diplonemid and euglenid) sequences, and grey circles to comparisons of basal kinetoplastid versus outgroup sequences. (c) The same as in (b) but with small points representing intragroup comparisons, open circles comparisons of apical kinetoplastid versus outgroup sequences, and grey circles comparisons of apical versus basal kinetoplastid sequences. 


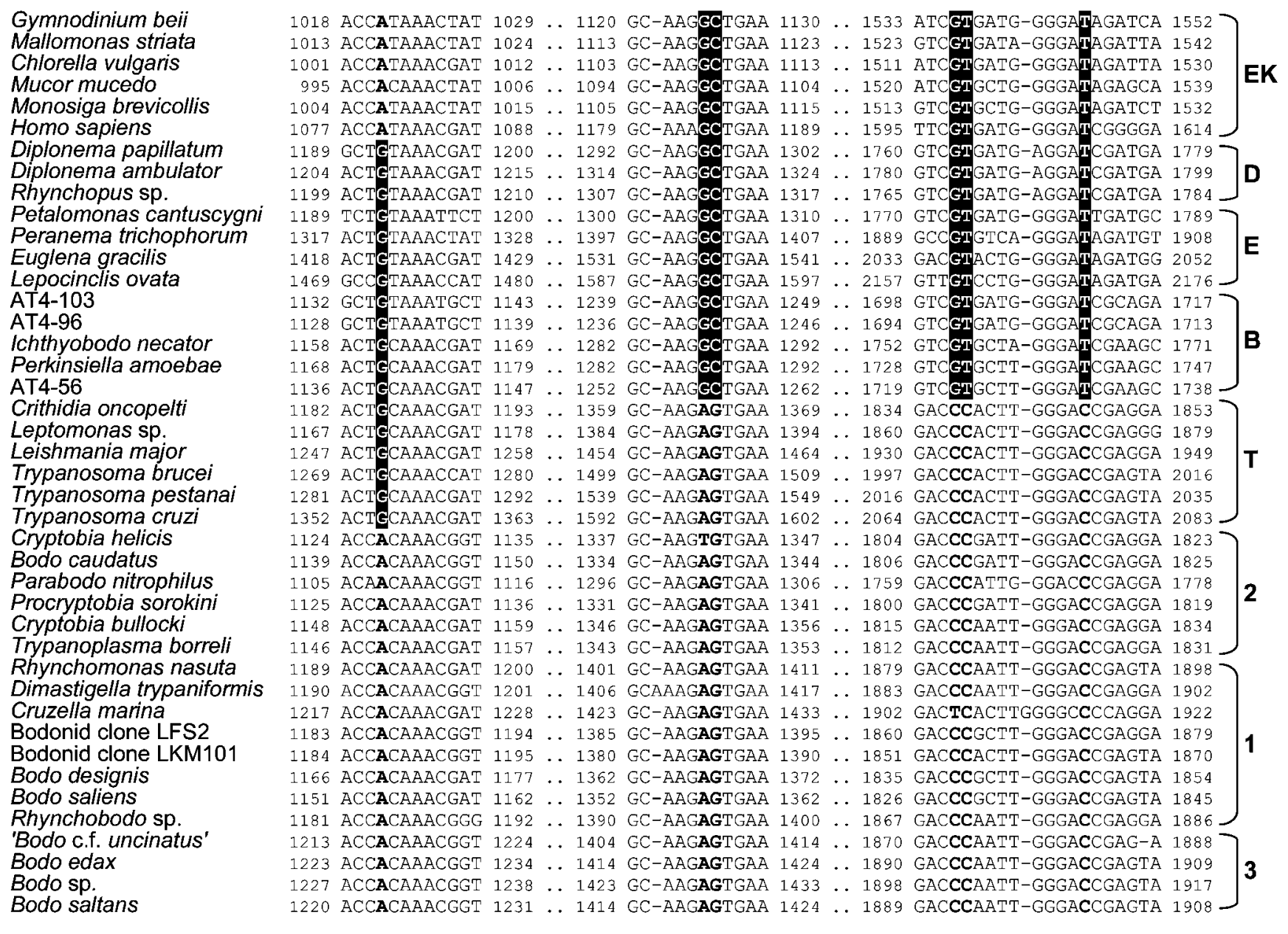

Fig. 2. Alignment of several regions of the $18 \mathrm{~S}$ rRNA gene from several slow-evolving eukaryotes (EK), diplonemids (D), euglenids (E), basal bodonids (B), trypanosomatids (T) and apical bodonids of the clades 1 (1), 2 (2) and 3 (3). Numbers on the right and left of the sequence fragments are the distances (in nucleotides) to the ends of the sequences. Gaps are indicated by dashes. Positions with black background correspond to signatures supporting the separation of basal bodonids and trypanosomatids from the rest of kinetoplastids (first alignment segment) or the basal position of the early emerging kinetoplastid sequences (second and third alignment segments).

sequences. To further increase the kinetoplastid taxonomic sampling, we have included four additional apical-branching $18 \mathrm{~S}$ rRNA environmental sequences also recovered from our analysis of deep-sea hydrothermal vent samples (LópezGarcía et al., 2003). Notably, the groups that emerge as monophyletic in unrooted analyses (Simpson et al., 2002) are also monophyletic in this rooted tree (although with a noticeable decrease of bootstrap support for clade 1, from $99 \%$ down to $77 \%$ for ML bootstrap values). The internal topologies for these groups are also in agreement with those found in unrooted analyses, with the exception of the preference in our trees for the grouping of Procryptobia sorokini at the base of a group containing B. caudatus, Cryptobia helicis and Parabodo nitrophilus within clade 2. Therefore, it appears that the use of these closer outgroup sequences to root the apical kinetoplastid tree has a positive effect. To test this hypothesis further, we have carried out several additional Bayesian analyses with different sets of ingroup and outgroup sequences, but without varying the alignment and the alignment positions used (not shown). First, to test whether the monophyly of the apical groups was the result of the incorporation of the four apicalbranching environmental sequences rather than of the use of a closer outgroup, we reconstructed a tree with similar settings but excluding these sequences. As for the complete dataset, the new tree also retrieved the monophyly of the apical groups, although with lower posterior probabilities (PPs) for the trypanosomatids and clade 1 bodonids $(0.67$ and 0.60 , respectively). This result suggests that the inclusion of the apical bodonid environmental sequences is not the major factor in retrieving the monophyly of the apical groups. Second, we reconstructed trees with the apical sequences plus different combinations of outgroup sequences. A tree rooted on diplonemid sequences retrieved 


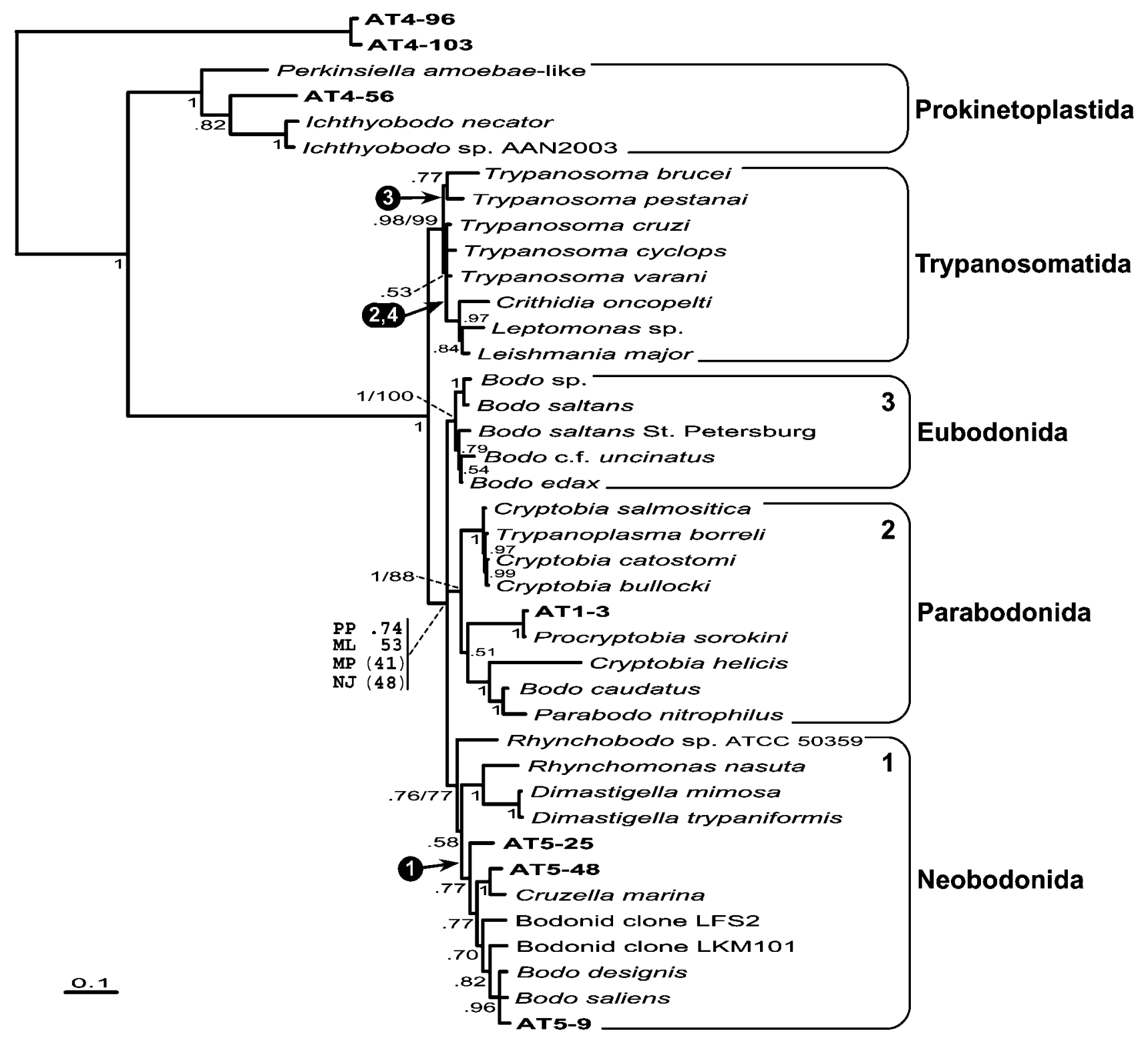

Fig. 3. Bayesian phylogenetic tree of apical kinetoplastid 18S rRNA sequences rooted on several basal sequences. Environmental sequences from deep-sea hydrothermal settings are in bold. Numbers at nodes are posterior probabilities except for the node concerning the split between the trypanosomatids and the apical bodonids, for which the PP and ML, MP and distance- (NJ) bootstrap proportions are shown (numbers in parentheses indicate that the node was not recovered in the MP and NJ analyses). ML bootstrap proportions are also shown for the nodes supporting the monophyly of the four apical kinetoplastid groups. The numbers on a black background indicate the position of the root for the apical kinetoplastids found in alternative trees rooted with (1) diplonemids, (2) diplonemids plus the basal sequences, (3) the Ichthyobodo-Perkinsiella clade only, and (4) diplonemids plus the Ichthyobodo-Perkinsiella clade. The apical bodonid clades 1, 2 and 3 are named according to Simpson et al. (2002). The names of the five kinetoplastid orders proposed in our new classification are indicated on the right. The tree was constructed using 1333 aligned sites. The scale bar represents the number of substitutions per position.

a basal paraphyletic emergence of clade 1 bodonids, while the trees rooted on (i) diplonemids plus the basal sequences, (ii) the Ichthyobodo-Perkinsiella clade only and (iii) the Ichthyobodo-Perkinsiella clade plus diplonemids retrieved all of them a basal paraphyletic emergence of trypanosomatids, i.e. a rooting of the apical kinetoplastids within the trypanosomatids (Fig. 3). Interestingly, a study supporting a similar rooting within the trypanosomatids has been published recently (Hughes \& Piontkivska, 2003). Our results suggest that this rooting is probably due to the use of a very distant 
outgroup. In fact, our analyses strongly suggest that the use of the closely related basal kinetoplastid and environmental sequences as outgroup allows retrieving the monophyly of all the apical clades.

Nevertheless, the most remarkable feature of our tree concerns the position of the root for the apical kinetoplastids, since the deepest node in this region of the tree separates the trypanosomatids from the rest of apical kinetoplastids. The best ML tree constructed using similar settings $(\mathrm{GTR}+\Gamma+I)$ displayed the same topology (not shown). However, GTR $+\Gamma+I-\mathrm{NJ}$ and $\mathrm{MP}$ trees showed a basal paraphyletic emergence of clade 2 bodonids, although with very low bootstrap support ( $<50 \%$, not shown).

The statistical support for the trypanosomatids versus apical bodonids split in our Bayesian and ML trees is weak, as also occurs for the relationships among the bodonid clades 1,2 and 3. Yet, this support is in the same range as, or even slightly higher than, those in other analyses favouring a late emergence of trypanosomatids nested within the bodonids (Callahan et al., 2002; Doležel et al., 2000; Simpson et al., 2002). We did not find support for the early emergence of clade 1 bodonids previously proposed on the basis of Hsp90 phylogenetic analyses (Simpson et al., 2002). The lack of strong support for the deep nodes of the tree is in agreement with the fact that alternative topologies showing a late emergence of trypanosomatids have similar likelihood values for our dataset (not shown). In addition, the majority-rule consensus tree constructed upon 1000 replicates in an ML bootstrapping analysis does not resolve the relationships between trypanosomatids and the bodonid clades 1, 2 and 3, since they all emerge within a multifurcation (not shown).

To look for additional support in favour or against this putative divergence between trypanosomatids and apical bodonids, we have analysed the conserved signature positions (i.e. those conserved in all sequences within monophyletic groups and polarizable using the outgroup sequences) in our extensive $18 \mathrm{~S}$ rRNA dataset. Only one perfect signature position can be found (corresponding to nucleotide 1223 in the sequence of $B$. saltans), which indeed supports the basal separation of trypanosomatids from the apical bodonids (see Fig. 2). No perfect signature position can be found supporting the monophyly of trypanosomatids and clade 3 bodonids, despite this being a relationship favoured by several phylogenetic analyses (Callahan et al., 2002; Simpson et al., 2002). We have also looked for signatures in the Hsp90 dataset used by Simpson et al. (2002). One position (corresponding to amino acid 107 in the complete sequence of Trypanosoma cruzi, GenBank accession number A26125) supports the separation of trypanosomatids from the apical bodonids, but three positions (41, 218 and 490) support a sisterhood relationship between trypanosomatids and clade 3 bodonids. Other signatures in positions showing more variable amino acid content also yield controversial support: position 485 supports a basal branching of trypanosomatids, while positions 535 and 604 support the sisterhood of trypanosomatids with clade 2 and/or clade 3 bodonids. Interestingly, in the kinetoplastid $18 \mathrm{~S}$ rRNA dataset used by these authors (Fig. 1a in their article), there is an additional signature (position 1226) supporting the basal emergence of trypanosomatids, but this signature disappears with the addition of our new sequences. This suggests that the larger number of sequence signatures observed in the Hsp90 dataset may be just due to the small number of Hsp90 sequences available, and that the future incorporation of new sequences may destroy some of these signatures. In summary, signatures appear to be too scarce and/or too equivocal to discern between the different alternative topologies.

Our results using the new slow-evolving basal kinetoplastid sequences reveal that the $18 \mathrm{~S}$ rRNA does not give privileged support to the classical hypothesis of the late origin of trypanosomatids nested within the bodonids. Therefore, it appears that the resolution of the position of the trypanosomatids in the kinetoplastid tree is still an open question since radically different tree topologies cannot be excluded with the available data. The solution to this query will most likely come from the analysis of alternative protein markers for a wide variety of species, including I. necator and other early emerging ones.

\section{Structural and genetic evolution in the Kinetoplastea}

The enigmatic origin and evolution of the kDNA and RNA editing have been debated for a long time (e.g. CavalierSmith, 1997; Doležel et al., 2000; Lukeš et al., 2002; Maslov et al., 1994; Simpson et al., 2000, 2002; Vickerman, 1990, 2000). A robust phylogenetic tree for the kinetoplastids is a logical prerequisite to address this question. The most recent analyses prioritize the hypothesis of a late origin of trypanosomatids as sister-group of bodonid species such as B. saltans (Callahan et al., 2002; Simpson et al., 2002). This view has important implications regarding the evolution of kDNA. In this phylogenetic scheme, the characteristic catenation of the kDNA minicircles in the trypanosomatids would most likely be a derived trait. However, the relaxed open-conformation minicircles found in trypanosomatids and certain clade 1 and clade 3 bodonids do not have a clear origin, although it has been suggested that the most parsimonious scenario would be that this exceptional DNA conformation was ancestral in the kinetoplastids (Simpson et al., 2002). The ancestral organization of the kDNA as a eukinetoplast, pankinetoplast or polykinetoplast is also uncertain.

We have seen that, although not robustly rejected, this phylogenetic framework is not strongly favoured by the newly available $18 \mathrm{~S}$ rRNA data. At any rate, the identification of $I$. necator and its allies as an outgroup for the apical kinetoplastids opens the way to solve these questions. Unfortunately, little is known about the characteristics of the kDNA and the existence of RNA editing in these basal bodonids. I. necator appears to possess polykinetoplast 
kDNA (Joyon \& Lom, 1969), while 'Perkinsiella cf. amoebae' shows a particular kDNA structure that also resembles to a certain extent a polykinetoplast kDNA (Dyková et al., 2003). This would suggest that this was the ancestral kDNA state in the kinetoplastids, which is at odds with the hypothesis that pankinetoplast kDNA is ancestral (Lukeš et al., 2002). Nevertheless, the bodonid clade 1 shows a mixture of polykinetoplast and eukinetoplast species, suggesting that the conversion between these two conformations may occur. The presence of polykinetoplast kDNA in I. necator and several apical bodonids might be therefore not necessarily ancestral but the result of convergence. No data are available about the topological status (relaxed or supercoiled) of the kDNA in this species, so that the question about the ancestrality of the open-conformation minicircles remains unsettled. Examination of this trait in I. necator and 'Perkinsiella cf. amoebae' becomes an urgent task to solve this query.

An appealing deduction from the classical 18S rRNA-based phylogenies was that trypanosomatids, being nested among bodonids, derive from a biflagellate ancestor (Doležel et al., 2000; Vickerman, 2000). Despite the lack of resolution for the apical region of the kinetoplastid tree and the possibility for other alternative topologies to be correct, the indisputable basal emergence of I. necator lends a robust support to this hypothesis.

\section{Taxonomic implications}

As noted in the Introduction, different taxonomic schemes have been proposed to classify the kinetoplastids. The most widespread one, namely the distinction of the two suborders Trypanosomatina and Bodonina (Vickerman, 1976), has been challenged recently by several authors who recommend abandoning the suborder Bodonina because the emergence of the trypanosomatids within it renders the group nonmonophyletic (Callahan et al., 2002; Simpson et al., 2002). Our analysis of a larger $18 \mathrm{~S}$ rRNA dataset keeps open the possibility that the species that we have called the 'apical' bodonids form a monophyletic group, though with moderate statistical support (Fig. 3). More data, in particular from protein sequences, are necessary to resolve the relationships among the apical kinetoplastid groups. At any rate, our analyses demonstrate the necessity of the erection of a new group to accommodate I. necator, as already suggested by Callahan et al. (2002), as well as 'Perkinsiella cf. amoebae'. Actually, the phylogenetic position of these basal species and their wide evolutionary distance from the rest of bodonids strongly advocate for their own taxonomic status within the Kinetoplastea, which is not contemplated by any of the current taxonomic schemes. Consequently, we propose the division of the class Kinetoplastea into two new subclasses - Prokinetoplastina, including the genera Ichthyobodo and Perkinsiella, and Metakinetoplastina, including the apical kinetoplastid genera (see below). This major division implies the adoption of new orders to accommodate these apical kinetoplastids. Thus, we propose to classify the Metakinetoplastina within four orders, the
Trypanosomatida and three new orders: Eubodonida, Parabodonida and Neobodonida, which correspond to the three major bodonid clades retrieved in our analyses (Fig. 3). The future determination of the precise position of the root of the apical part of the kinetoplastid tree should not affect the stability of this classification, since this information can easily be accommodated simply by the erection of two superorders within the subclass Metakinetoplastina.

Neither the subdivision of the former suborder Bodonina into the two families Bodonidae and Cryptobiidae (Vickerman, 1976) nor the two subfamilies Bodoninae and Cryptobiinae (Zhukov, 1991) are compatible with the $18 \mathrm{~S}$ rRNA- and Hsp90-based phylogenetic trees. These molecular phylogenies support several robust monophyletic groups, in particular the clades 2 and 3 (Fig. 1 and 3). Clade 2 corresponds to the new order Parabodonida and clade 3 to the new order Eubodonida. The latter groups several isolates of $B$. saltans and the dubiously distinct isolates labelled Bodo edax and 'B. c.f. uncinatus' (see notes to the updated classification of the Kinetoplastea below). Given their different feeding habits, behaviour, and flagellar and oral structure (Brooker, 1971), it is not surprising that they branch far from the other Bodo species (B. caudatus, Bodo saliens and $B$. designis), belonging to the other two new bodonid orders Parabodonida and Neobodonida (see below). Therefore, if the generic name Bodo is retained for the type species $B$. saltans, the distant species B. caudatus, B. saliens and $B$. designis should be classified within at least two different genera (see the updated classification of the genus Bodo below). A similar situation is found for the genus Cryptobia, since the type species, Cryptobia helicis, does not form a monophyletic group with the marine fish parasites (C. bullocki, C. catostomi and C. salmositica). C. helicis possesses pankinetoplast $\mathrm{kDNA}$, which is different from the unusual 'megakinetoplast' kDNA from Trypanoplasma and the marine cryptobias (Lukeš et al., 1998). These marine cryptobias could be reclassified within the genus Trypanoplasma, which would be in agreement with the idea that most Cryptobia spp. and Trypanoplasma should be united into a single genus (Vickerman, 1976, 1990, 2000; Woo, 1987). More sequences are now needed from cryptobias of non-molluscan invertebrate hosts (e.g. C. vaginalis from leeches), however, to clarify the phylogenetic isolation of Cryptobia helicis. Nevertheless, even with these amendments, the family Cryptobiidae (also including the genera Procryptobia and Dimastigella) would remain polyphyletic and should be abandoned. It appears that attachment of the recurrent flagellum (or loss of attachment) may have evolved more than once.

A genus that has been particularly problematic is Rhynchobodo. This genus almost uniquely among kinetoplastids possesses extrusomes (trichocysts) similar to those of euglenids and diplonemids (Brugerolle, 1985). The only molecular data available for this genus is the 18S rRNA sequence of the species Rhynchobodo sp. ATCC 50359 
(Lukeš et al., 1997). This sequence has shown an unstable position in previous phylogenetic analyses (e.g. Atkins et al., 2000; Doležel et al., 2000; Simpson et al., 2002), being even possible that the root of the apical part of the kinetoplastid tree lies between this species and the rest of clade 1 bodonids (as in one of the ML trees shown by Simpson et al., 2002). However, our trees rooted with closer outgroup sequences show a much more stable position of this species at the base of the clade 1 bodonids although with moderate statistical support (Fig. 3). We suggest therefore that it is a member of the new order Neobodonida. An additional problem concerning this species is that the generic assignment of Rhynchobodo sp. ATCC 50359 might be questionable, since no detailed morphological data are available for this strain (Simpson et al., 2002). The examination of this ATCC isolate by one of us (K. Vickerman, unpublished data) authenticates its ascription to the genus Rhynchobodo, which therefore would be part of the order Neobodonida.

\section{The position of the Kinetoplastea within the Euglenozoa}

The new basal kinetoplastid sequences can be useful also to address the question of the deep phylogenetic relationships between the three euglenozoan classes, Euglenoidea, Diplonemea and Kinetoplastea. Since the basal sequences display significantly shorter branches than the rest of kinetoplastids (Fig. 1a), we have used them as slowevolving representatives for the entire class Kinetoplastea, following a strategy already applied by others to resolve the phylogenetic position of fast-evolving lineages (Aguinaldo et al., 1997). The Bayesian analysis of a dataset incorporating four diplonemids, four euglenids, four basal kinetoplastids and several slow-evolving representatives from other eukaryotic taxa retrieves a tree showing the sisterhood of kinetoplastids and diplonemids with a weak to strong statistical support (Fig. 4). The high PP (0.95) assigned by the Bayesian analysis to this relationship is especially noticeable, in contrast with the weak support found by the other methods (bootstrap proportions between 51 and $61 \%$ ). Disagreements between posterior probabilities calculated by Bayesian analysis and bootstrap support are frequent (Alfaro et al., 2003; Douady et al., 2003; Suzuki et al., 2002), so we cannot draw conclusions about the robustness of this node. Other Bayesian trees constructed using diverse apical species as representatives of the Kinetoplastea also retrieve the sisterhood of kinetoplastids and diplonemids, although

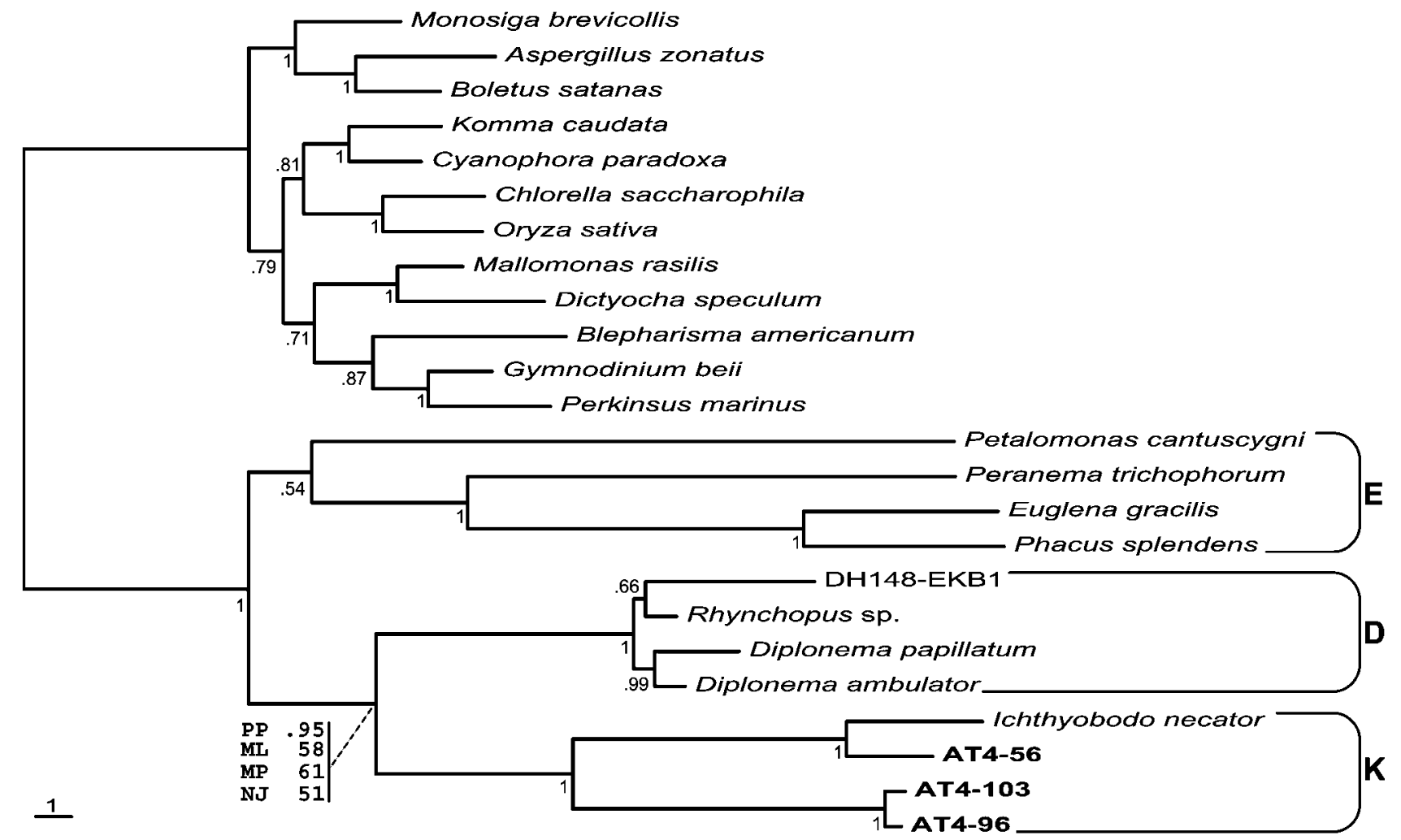

Fig. 4. Bayesian phylogenetic tree of euglenozoan $18 \mathrm{~S}$ rRNA sequences rooted on several slow-evolving eukaryotic species. Environmental sequences from deep-sea hydrothermal settings are in bold. Numbers at nodes are posterior probabilities except for the node separating the diplonemids (D) and kinetoplastids (K) from the euglenids (E). For this node the PP and ML, MP and distance- (NJ) bootstrap proportions are shown. The tree was constructed using 1150 aligned sites. The scale bar represents the number of substitutions per position. 
with lower posterior probabilities (between $0 \cdot 71$ and $0 \cdot 90$, not shown).

The sisterhood of kinetoplastids and diplonemids is in disagreement with our previous analysis of the euglenozoan internal phylogeny, which moderately supported an alternative diplonemids + euglenids relationship (Moreira et al., 2001). However, in contrast with this previous analysis, the kinetoplastids + diplonemids clade retrieved here appears to be less sensitive to $\mathrm{G}+\mathrm{C}$ bias since it is repeatedly found using a variety of outgroup sequences with diverse $G+C$ composition (not shown). Such a clade joining kinetoplastids and diplonemids would be congruent with previous $18 \mathrm{~S}$ rRNA-based euglenozoan phylogenies (Maslov et al., 1999) and especially with recent phylogenies based on protein sequences that provide very strong support for this relationship (Simpson \& Roger, 2004).

A remarkable feature of the euglenozoan tree is the weak bootstrap support for the monophyly of the euglenids. Moreover, a proportion of the best-scored ML trees supports the emergence of the kinetoplastids + diplonemids clade within the euglenids, although this result might be due to LBA artefacts instead of true phylogenetic signal since the 18S rRNA sequences available for most basal euglenids (Eutreptiales, Rhabdomonadales, Sphenomonadales and Heteronematales) are extremely divergent (Busse \& Preisfeld, 2002a, b; Preisfeld et al., 2001). Nevertheless, the idea that the clade composed of kinetoplastids plus diplonemids could have had its origin from within the euglenids can be appealing, in particular because of the recent discovery of genes of possible chloroplast origin in the genome of trypanosomatid species (Hannaert et al., 2003), which suggests that kinetoplastids had a photosynthetic ancestor. To test this hypothesis, the identification of slow-evolving basal euglenids and/or the construction and analysis of sequence datasets of a variety of genes from a wide spectrum of members of the three euglenozoan subphyla are essential.

\section{Concluding remarks}

The culture-independent approach based on the direct amplification of $18 \mathrm{~S}$ rRNA genes from environmental samples has allowed us to detect three new sequences that, as occurs with those from the genera Ichthyobodo and Perkinsiella, emerge deeply on the kinetoplastid branch. In addition to their influence in breaking the otherwise unbroken long basal kinetoplastid branch, these sequences indicate that our knowledge on the diversity of the kinetoplastids probably remains very limited. $18 \mathrm{~S}$ rRNA-based surveys can be a rapid way to get insight into kinetoplastid diversity. It is interesting to note that, despite the publication of several of such surveys, most of them of marine environments (Amaral Zettler et al., 2002; Dawson \& Pace, 2002; Edgcomb et al., 2002; López-García et al., 2001; Moon-van der Staay et al., 2001; Stoeck \& Epstein, 2003), our study of deep-sea hydrothermal environments has been the first to yield kinetoplastid sequences (López-García et al., 2003). Given the profusion of kinetoplastid species in nature (Arndt et al., 2000; Foissner, 1991; Vickerman, 2000), this result might probably reflect a PCR bias against the amplification of kinetoplastid rRNA genes. Surveys using kinetoplastid-specific primers will overcome this possible limitation and will most likely continue to increase the kinetoplastid rRNA dataset.

Our limited knowledge on kinetoplastid diversity seems to be a major reason for the observation of a very long basal kinetoplastid branch, although alternative explanations involving a dramatic acceleration of evolutionary rate at the origin of the kinetoplastids may have also been partially responsible. However, we can discard the hypothesis of the extinction of all intermediate lineages. At least two early emerging lineages (the first defined by the environmental sequences AT4-96 and AT4-103, and the second by I. necator, 'Perkinsiella cf. amoebae' and the environmental sequence AT4-56, i.e. the new subclass Prokinetoplastina) still exist. Isolation of the organisms for which we have just retrieved their $18 \mathrm{~S}$ rRNA sequences, and their subsequent detailed characterization (which remains also necessary for I. necator and 'Perkinsiella cf. amoebae') will be central to our understanding of the origin and early evolution of the kinetoplastids.

\section{Updated classification of the class Kinetoplastea ${ }^{a}$}

\section{Class Kinetoplastea Honigberg 1963 emend. Vickerman 1976}

Subclass: Prokinetoplastina subclass nov. Vickerman ${ }^{\text {b }}$ Diagnosis: An independent early emerging clade in $18 \mathrm{~S}$ rRNA phylogenies. Most recent common ancestor of Ichthyobodo and Perkinsiella. Polykinetoplastic.

Order: Prokinetoplastida ord. nov. Vickerman. With characters of subclass. Two genera: Ichthyobodo and Perkinsiella. ${ }^{\mathrm{c}}$

Subclass: Metakinetoplastina subclass nov. Vickerman. Diagnosis: An independent late-emerging clade in $18 \mathrm{~S}$ rRNA phylogenies. Most recent common ancestor of Bodo, Cryptobia, Trypanoplasma, Procryptobia, Rhynchobodo, Dimastigella, Crithidia, Leishmania and Trypanosoma. Eukinetoplastic, pankinetoplastic or polykinetoplastic. Free-living and parasitic species described.

Order 1. Eubodonida ord. nov. Vickerman ${ }^{\mathrm{d}}$. Diagnosis: Eukinetoplastic; kDNA circles not forming a network. Biflagellate. Anterior flagellum bears non-tubular hairs; posterior flagellum lacks hairs, free from body. Phagotrophic. Cytostome anterolateral, surrounded by lappets; marked preoral ridge absent; cytopharynx traverses body. Free-living species described. One genus: Bodo.

Order 2. Parabodonida ord. nov. Vickerman ${ }^{\mathrm{e}}$. Diagnosis: Pankinetoplastic/eukinetoplastic (have potential for pankinetoplastic distribution of $\mathrm{kDNA}$ ); $\mathrm{kDNA}$ circles do not 
form a network. Biflagellate; both flagella lack hairs; posterior flagellum attached to body or free from it. Phagotrophic or osmotrophic. Cytostome anterolateral, usually with prominent preoral ridge. Free-living and parasitic species described. Most recent common ancestor of Parabodo [includes Parabodo caudatus comb. nov., basionym Bodo caudatus (Stein, 1878), Cryptobia, Procryptobia and Trypanoplasma].

Order 3. Neobodonida ord. nov. Vickerman ${ }^{\mathrm{f}}$. Diagnosis: Polykinetoplastic or eukinetoplastic. Biflagellate; usually both flagella lack hairs. Posterior flagellum attached to body or free of it. Phagotrophic. Cytostome apical, associated with conspicuous development of preflagellar rostrum. Free-living species (some possibly endocommensal). Most recent common ancestor of Neobodo gen. nov. [includes Neobodo designis comb. nov., basionym Bodo designis (Skuja, 1948), Rhynchobodo, Rhynchomonas, Dimastigella and Cruzella].

Order 4. Trypanosomatida Kent 1880 stat. nov. Hollande 1952 ${ }^{\mathrm{g}}$. Diagnosis: Eukinetoplastic; $\mathrm{kDNA}$ in form of a network of catenated circles. Uniflagellate, flagellum hairless and emerging from pocket at anterior end of body or emerging laterally and attached to body along much of its length. Osmotrophic. Cytostome, if present, close to flagellar pocket, lacks associated oral structures. All species parasitic. Most recent common ancestor of Leptomonas, Herpetomonas, Crithidia, Blastocrithidia, Rhynchoidomonas, Phytomonas, Leishmania, Sauroleishmania, Endotrypanum, Wallaceina and Trypanosoma.

${ }^{\text {a}}$ Honigberg's order Kinetoplastida is treated here as subclass Kinetoplastea within the phylum Euglenozoa Cavalier-Smith.

${ }^{\mathrm{b}}$ In this updated view, the class is divided into two subclasses, Prokinetoplastina ('Pro-' signifying early branching) and Metakinetoplastina ('Meta-' signifying later), on the basis of gene sequences. Environmental sequences AT4-103 and AT4-96 would presumably belong to a third subclass.

'Ichthyobodo necator and 'Perkinsiella cf. amoebae' are reasonably well characterized morphologically, but the molecular organization of their kinetoplasts is unknown.

'Eubodonidae: 'Eu-' signifying true, as the type species of Ehrenberg's genus Bodo, B. saltans figures prominently in this group. The 'Bodo sp.' sequenced by Callahan et al. (2002) from the ATCC, and assigned to this clade (see Fig. 3), is undoubtedly also B. saltans. The nature of 'B. edax' and ' $B$. c.f. uncinatus' is more difficult to assess. Callahan et al. obtained these two isolates from the ATCC: both lack an associated published description. Klebs' (1892) Bodo edax description applies to a protoalveolate (Colpodella sp.). In the same publication, Klebs also changed SavilleKent's name Heteromita uncinatus to Bodo, having confused the two genera. Kent's species, however, had amoeboid activity, which does not occur in Bodo spp. but is characteristic of the cercomonad genus Heteromita. It appears likely that the two ATCC isolates are also B. saltans.

'Parabodonida: 'Para-' signifying alongside. This clade contains the species Bodo caudatus Stein and Parabodo nitrophilus Skuja. As separation of the former from the type species of the genus Bodo is now necessary, and the inclusion of $P$. nitrophilus in the same genus as Bodo caudatus has long been called for (Vickerman, 1976), it seems expedient to transfer $B$. caudatus to the genus Parabodo Skuja, 1939, further justifying the name of the new order. Intriguingly, this order contains all the genera of the former family Cryptobiidae (characterized by an attached recurrent flagellum) except Dimastigella. An interesting feature of this group is the potential for pankinetoplastic distribution of kDNA in the mitochondrion. This is evident in the cryptobias/trypanoplasms, but on encystation redistribution of kDNA into several masses occurs in Procryptobia glutinosa (Vickerman, 1978) and in a flagellate otherwise indistinguishable from Bodo caudatus (Brugerolle \& Mignot, 1979).

fNeobodonida: 'Neo-' signifying new. In many ways, this is the most puzzling clade of the three metakinetoplastid orders as it contains distinctly polykinetoplastic genera (Rhynchobodo and Dimastigella) and distinctly eukinetoplastic members (Rhynchomonas nasuta and Bodo designis). Bodo designis Skuja is well-studied ultrastructurally (Eyden, 1977). In its possession of a 'microtubular prism' supporting the cytostome-cytopharynx, it differs significantly in its feeding apparatus from both $B$. saltans and $P$. caudatus and its location in a different order from the former necessitates a new generic designation. It is proposed to make it the type species of the new genus Neobodo as indicated below (see updated classification of the genus Bodo). Bodo curvifilis, which also possesses a microtubular prism (Burzell, 1975), probably belongs in this genus. Bodo saliens has been described on the basis of size and behaviour only; the nature of its kinetoplast is undescribed as is its ultrastructure and, although it and other former Bodo spp. of this clade may tentatively be assigned to the genus Neobodo, creation of independent genera may eventually prove necessary. The genera Rhynchobodo, Dimastigella and Rhynchomonas are well characterized ultrastructurally (Brugerolle, 1985; Breunig et al., 1993; Swale, 1973), the first two being polykinetoplastic, the last eukinetoplastic. Kinetoplast molecular organization has been studied only for Dimastigella (Štolba et al., 2001) and the ATCC flagellate labelled Cruzella marina (Zíková et al., 2003) also known to be polykinetoplastic (Frolov \& Malysheva, 2002). In both these genera the minicircles are distributed in multiple discrete loci spread throughout the mitochondrion, but within each locus the circles are uncatenated.

gOrder Trypanosomatida; corresponds exactly to the suborder Trypanosomatina and family Trypanosomatidae of previous classifications. 


\section{Updated classification of the genus Bodo}

Diagnosis of the genera: The genus Bodo as presently constituted is clearly polyphyletic with species in three separate well-supported clades and demands revision. It is here proposed that the species in the three separate orders should be assigned to three different genera as follows.

Genus: Bodo Ehrenberg 1830 emend. Vickerman. Solitary phagotrophic flagellates with single discrete eukinetoplast. Recurrent flagellum free from the body and used in saltatory movements when not free-swimming. Lateral cytostomecytopharynx lacks supporting prismatic rod. Type species: Bodo saltans Ehrenberg.

Genus: Parabodo Skuja 1939 emend. Vickerman. Solitary phagotrophic flagellates with kDNA arranged in eukinetoplast in trophic flagellate, but becoming dispersed as pankinetoplast in encysted stage. Body flattened. Recurrent flagellum free or mainly free from body and used as a skid when not free-swimming. Cytostome-cytopharynx lacks supporting prismatic rod. Type species: Parabodo sacculifera Skuja 1939.

Genus: Neobodo gen. nov. Vickerman. Solitary phagotrophic flagellates with a single discrete eukinetoplast. Recurrent flagellum free or mainly free from body and used as a skid when not free-swimming. Apical cytostome and cytopharynx supported by prismatic rod of microtubules. Type species: Neobodo designis (Skuja) Vickerman comb. nov.

\section{ACKNOWLEDGEMENTS}

This work was supported by GEOMEX (CNRS/INSUE) and ATIP (CNRS) grants to P.L.-G. K.V. is a Leverhulme Trust Emeritus Research Fellow. We thank A. G. B. Simpson and A. J. Roger for sharing preprints. J. Lukeš and an anonymous reviewer provided useful data and many valuable suggestions.

\section{REFERENCES}

Aguinaldo, A. M., Turbeville, J. M., Linford, L. S., Rivera, M. C., Garey, J. R., Raff, R. A. \& Lake, J. A. (1997). Evidence for a clade of nematodes, arthropods and other moulting animals. Nature 387, 489-493.

Alfaro, M. E., Zoller, S. \& Lutzoni, F. (2003). Bayes or bootstrap? A simulation study comparing the performance of Bayesian Markov chain Monte Carlo sampling and bootstrapping in assessing phylogenetic confidence. Mol Biol Evol 20, 255-266.

Amaral Zettler, L. A., Gomez, F., Zettler, E., Keenan, B. G., Amils, R. \& Sogin, M. L. (2002). Microbiology: eukaryotic diversity in Spain's River of Fire. Nature 417, 137.

Arndt, H., Dietrich, D., Auer, B., Cleven, E., Grafenham, T., Weitere, M. \& Mylnikov, A. P. (2000). Functional diversity of heterotrophic flagellates in aquatic ecosystems. In The Flagellates, pp. 240-268. Edited by B. S. C. Leadbeater \& J. C. Green. London: Taylor \& Francis.

Atkins, M. S., Teske, A. P. \& Anderson, O. R. (2000). A survey of flagellate diversity at four deep-sea hydrothermal vents in the Eastern
Pacific Ocean using structural and molecular approaches. J Eukaryot Microbiol 47, 400-411.

Blom, D., de Haan, A., van den Berg, M., Sloof, P., Jirků, M., Lukeš, J. \& Benne, R. (1998). RNA editing in the free-living bodonid Bodo saltans. Nucleic Acids Res 26, 1205-1213.

Breunig, A., König, H., Brugerolle, G., Vickerman, K. \& Hertel, H. (1993). Isolation and ultrastructural features of a new strain of Dimastigella trypaniformis Sandon 1928 (Bodonina, Kinetoplastida) and comparison with a previously isolated strain. Eur J Protistol 29, 416-424.

Brooker, B. E. (1971). Fine structure of Bodo saltans and Bodo caudatus (Zoomastigophora, Protozoa) and their affinities with the Trypanosomatidae. Bull Brit Mus (Nat Hist) 22, 89-102.

Brugerolle, G. (1985). Des trichocystes chez les bodonides, un caractère phylogénétique supplémentaire entre Kinetoplastida et Euglenida. Protistologica 21, 339-348.

Brugerolle, G. \& Mignot, J.-P. (1979). Distribution et organisation de l'ADN dans le complex kinétoplaste-mitochondrie chez un Bodonidé, protozoaire kinétoplastidé; variations au cours du cycle cellulaire. Biol Cell 35, 111-114.

Burzell, L. A. (1975). Fine structure of Bodo curvifilus Griessmann (Kinetoplastida: Bodonidae). J Protozool 22, 35-39.

Busse, I. \& Preisfeld, A. (2002a). Phylogenetic position of Rhynchopus sp. and Diplonema ambulator as indicated by analyses of euglenozoan small subunit ribosomal DNA. Gene 284, 83-91.

Busse, I. \& Preisfeld, A. (2002b). Unusually expanded SSU ribosomal DNA of primary osmotrophic euglenids: molecular evolution and phylogenetic inference. J Mol Evol 55, 757-767.

Callahan, H. A., Litaker, R. W. \& Noga, E. J. (2002). Molecular taxonomy of the suborder Bodonina (Order Kinetoplastida), including the important fish parasite, Ichthyobodo necator. $J$ Eukaryot Microbiol 49, 119-128.

Cavalier-Smith, T. (1981). Eukaryote kingdoms: seven or nine? Biosystems 14, 461-481.

Cavalier-Smith, T. (1997). Cell and genome coevolution: facultative anaerobiosis, glycosomes and kinetoplastan RNA editing. Trends Genet 13, 6-9.

Dawson, S. C. \& Pace, N. R. (2002). Novel kingdom-level eukaryotic diversity in anoxic environments. Proc Natl Acad Sci U S A 99, 8324-8329.

Doležel, D., Jirků, M., Maslov, D. A. \& Lukeš, J. (2000). Phylogeny of the bodonid flagellates (Kinetoplastida) based on small-subunit rRNA gene sequences. Int J Syst Evol Microbiol 50, 1943-1951.

Douady, C. J., Delsuc, F., Boucher, Y., Doolittle, W. F. \& Douzery, E. J. (2003). Comparison of Bayesian and maximum likelihood bootstrap measures of phylogenetic reliability. Mol Biol Evol 20, 248-254.

Dyková, I., Fiala, I., Lom, J. \& Lukeš, J. (2003). Perkinsiella amoebaelike endosymbionts of Neoparamoeba spp., relatives of the kinetoplastid Ichthyobodo. Eur J Protistol 39, 37-52.

Edgcomb, V. P., Kysela, D. T., Teske, A., de Vera Gomez, A. \& Sogin, M. L. (2002). Benthic eukaryotic diversity in the Guaymas Basin hydrothermal vent environment. Proc Natl Acad Sci U S A 99, 7658-7662.

Eyden, B. P. (1977). Morphology and ultrastructure of Bodo designis Skuja 1948. Protistologica 13, 169-179.

Foissner, W. (1991). Diversity and ecology of soil flagellates. In The Biology of Free-living Heterotrophic Flagellates, pp. 93-112. Edited by D. J. Patterson \& J. Larsen. New York: Clarendon Press.

Frolov, A. O. \& Malysheva, M. N. (2002). Ultrastructure of the flagellate Cruzella marina (Kinetoplastidea). Tsitologiia 44, 477-484 (in Russian). 
Hannaert, V., Saavedra, E., Duffieux, F., Szikora, J. P., Rigden, D. J., Michels, P. A. \& Opperdoes, F. R. (2003). Plant-like traits associated with metabolism of Trypanosoma parasites. Proc Natl Acad Sci U S A 100, 1067-1071.

Hendy, M. D. \& Penny, D. (1989). A framework for the quantitative study of evolutionary trees. Syst Zool 38, 297-309.

Hollande, A. (1952). Ordre des Bodonides (Bodonidea ord. nov.). In Traité de Zoologie, pp. 669-693. Edited by P. P. Grassé. Paris: Masson \& Cie.

Honigberg, B. M. (1963). A contribution to systematics of the non-pigmented flagellates. In Progress in Protozoology, p. 68. Edited by J. Ludvik, J. Lom \& J. Vavra. New York: Academic Press.

Huelsenbeck, J. P. \& Ronquist, F. (2003). MrBayes: a program for the Bayesian inference of phylogeny. Uppsala: Uppsala University.

Hughes, A. L. \& Piontkivska, H. (2003). Phylogeny of Trypanosomatidae and Bodonidae (Kinetoplastida) based on 18S rRNA: evidence for paraphyly of Trypanosoma and six other genera. Mol Biol Evol 20, 644-652.

Joyon, L. \& Lom, J. (1969). Etude cytologique, systématique et pathologique d'Ichthyobodo necator (Henneguy 1883) Pinto 1928 (Zooflagellé). J Protozool 6, 703-719.

Klebs, G. (1892). Flagellatenstudien. Z Wiss Zool 55, 265.

Landweber, L. F. \& Gilbert, W. (1994). Phylogenetic analysis of RNA editing: a primitive genetic phenomenon. Proc Natl Acad Sci U S A 91, 918-921.

López-García, P., Rodríguez-Valera, F., Pedrós-Alió, C. \& Moreira, D. (2001). Unexpected diversity of small eukaryotes in deep-sea Antarctic plankton. Nature 409, 603-607.

López-Garcia, P., Philippe, H., Gaill, F. \& Moreira, D. (2003). Autochthonous eukaryotic diversity in hydrothermal sediment and experimental micro-colonizers at the Mid-Atlantic Ridge. Proc Natl Acad Sci U S A 100, 697-702.

Lukeš, J., Jirků, M., Doležel, D., Kral'ova, I., Hollar, L. \& Maslov, D. A. (1997). Analysis of ribosomal RNA genes suggests that trypanosomes are monophyletic. J Mol Evol 44, 521-527.

Lukeš, J., Jirků, M., Avliyakulov, N. \& Benada, O. (1998). Pankinetoplast DNA structure in a primitive bodonid flagellate, Cryptobia helicis. EMBO J 17, 838-846.

Lukeš, J., Guilbride, D. L., Votypka, J., Zikova, A., Benne, R. \& Englund, P. T. (2002). Kinetoplast DNA network: evolution of an improbable structure. Eukaryot Cell 1, 495-502.

Maslov, D. A., Avila, H. A., Lake, J. A. \& Simpson, L. (1994). Evolution of RNA editing in kinetoplastid protozoa. Nature 368, 345-348.

Maslov, D. A., Yasuhira, S. \& Simpson, L. (1999). Phylogenetic affinities of Diplonema within the Euglenozoa as inferred from the SSU rRNA gene and partial COI protein sequences. Protist 150, $33-42$.

Moon-van der Staay, S. Y., De Wachter, R. \& Vaulot, D. (2001). Oceanic $18 \mathrm{~S}$ rDNA sequences from picoplankton reveal unsuspected eukaryotic diversity. Nature 409, 607-610.

Moreira, D., López-Garcia, P. \& Rodríguez-Valera, F. (2001). New insights into the phylogenetic position of diplonemids: $\mathrm{G}+\mathrm{C}$ content bias, differences of evolutionary rate, and a new environmental sequence. Int J Syst Evol Microbiol 51, 2211-2219.

Philippe, H. (1993). MUST, a computer package of Management Utilities for Sequences and Trees. Nucleic Acids Res 21, 5264-5272.

Philippe, H. \& Adoutte, A. (1998). The molecular phylogeny of Eukaryota: solid facts and uncertainties. In Evolutionary Relationships among Protozoa, pp. 25-56. Edited by G. Coombs, K. Vickerman, M. Sleigh \& A. Warren. London: Chapman \& Hall.
Philippe, H. \& Germot, A. (2000). Phylogeny of eukaryotes based on ribosomal RNA: long-branch attraction and models of sequence evolution. Mol Biol Evol 17, 830-834.

Philippe, H. \& Laurent, J. (1998). How good are deep phylogenetic trees? Curr Opin Genet Dev 8, 616-623.

Philippe, H., Sörhannus, U., Baroin, A., Perasso, R., Gasse, F. \& Adoutte, A. (1994). Comparison of molecular and paleontological data in diatoms suggests a major gap in the fossil record. J Evol Biol 7, 247-265.

Philippe, H., Lopez, P., Brinkmann, H., Budin, K., Germot, A., Laurent, J., Moreira, D., Muller, M. \& Le Guyader, H. (2000). Early-branching or fast-evolving eukaryotes? An answer based on slowly evolving positions. Proc R Soc Lond B Biol Sci 267, 1213-1221.

Posada, D. \& Crandall, K. A. (1998). MODELTEST: testing the model of DNA substitution. Bioinformatics 14, 817-818.

Preisfeld, A., Busse, I., Klingberg, M., Talke, S. \& Ruppel, H. G. (2001). Phylogenetic position and inter-relationships of the osmotrophic euglenids based on SSU rDNA data, with emphasis on the Rhabdomonadales (Euglenozoa). Int J Syst Evol Microbiol 51, 751-758.

Shimodaira, H. (2002). An approximately unbiased test of phylogenetic tree selection. Syst Biol 51, 492-508.

Shimodaira, H. \& Hasegawa, M. (2001). CONSEL: for assessing the confidence of phylogenetic tree selection. Bioinformatics 17, 1246-1247.

Simpson, A. G. \& Roger, A. J. (2004). Protein phylogenies robustly resolve the deep-level relationships within Euglenozoa. Mol Phylogenet Evol 30, 201-212.

Simpson, A. G., Lukeš, J. \& Roger, A. J. (2002). The evolutionary history of kinetoplastids and their kinetoplasts. Mol Biol Evol 19, 2071-2083.

Simpson, L., Thiemann, O. H., Savill, N. J., Alfonzo, J. D. \& Maslov, D. A. (2000). Evolution of RNA editing in trypanosome mitochondria. Proc Natl Acad Sci U S A 97, 6986-6993.

Skuja, H. (1939). Beitrag sur Algenflora Lettlands II. Acta Horti Bot Univ Latv XI/XII, 41-169.

Skuja, H. (1948). Taxonomie des Phytoplanktons einiger Seen in Upplands, Schweden. Symb Bot Ups 9, 1-399.

Stein, F. R. (1878). Der Organismus der Infusionsthiere. III. Der Organismus der Flagellaten 1. Leipzig: Engelmann.

Stoeck, T. \& Epstein, S. (2003). Novel eukaryotic lineages inferred from small-subunit rRNA analyses of oxygen-depleted marine environments. Appl Environ Microbiol 69, 2657-2663.

Štolba, P., Jirků, M. \& Lukeš, J. (2001). Polykinetoplast DNA structure in Dimastigella trypaniformis and Dimastigella mimosa (Kinetoplastida). Mol Biochem Parasitol 113, 323-326.

Suzuki, Y., Glazko, G. V. \& Nei, M. (2002). Overcredibility of molecular phylogenies obtained by Bayesian phylogenetics. Proc Natl Acad Sci U S A 99, 16138-16143.

Swale, E. M. F. (1973). A study of the colourless flagellate Rhynchomonas nasuta (Stokes) Klebs. Biol J Linn Soc 5, 255-264.

Swofford, D. L. (2000). PAUP*, phylogenetic analysis using parsimony ( ${ }^{*}$ and other methods), version 4. Sunderland, MA: Sinauer Associates.

Vickerman, K. (1976). The diversity of the kinetoplastid flagellates. In Biology of the Kinetoplastida, pp. 1-34. Edited by W. H. R. Lumsden \& D. A. Evans. London: Academic Press.

Vickerman, K. (1978). The free-living trypanoplasms: descriptions of three species of the genus Procryptobia n.g., and redescription of Dimastigella trypaniformis Sandon, with notes on their relevance 
to the microscopical diagnosis of disease in man and animals. Trans Am Microsc Soc 97, 485-502.

Vickerman, K. (1990). Phylum Zoomastigina, class Kinetoplastida. In Handbook of Protoctista, pp. 215-238. Edited by L. Margulis, J. O. Corliss, M. Melkonian \& D. J. Chapman. Boston: Jones \& Bartlett.

Vickerman, K. (2000). Order Kinetoplastea. In The Illustrated Guide to the Protozoa, pp. 1159-1185. Edited by J. J. Lee, G. F. Leedale \& P. Bradbury. Lawrence, KS: Allen Press.
Woo, P. T. K. (1987). Cryptobia and cryptobiasis in fishes. Adv Parasitol 26, 199-237.

Zhukov, B. F. (1991). The diversity of bodonids. In The Biology of Free-living Heterotrophic Flagellates, pp. 177-184. Edited by D. J. Patterson \& J. Larsen. New York: Clarendon Press.

Zíková, A., Vancová, M., Jirků, M. \& Lukeš, J. (2003). Cruzella marina (Bodonina, Kinetoplastida): non-catenated structure of poly-kinetoplast DNA. Exp Parasitol 104, 159-161. 